\title{
THE COMPOSITION OF KILN GASES AND THEIR EFFECT ON TERRA COTTA GLAZES AND COLORS ${ }^{1}$
}

\author{
By F. B. Ortman
}

Every manufacturer of architectural terra cotta is aware of the difficulties attendant upon any effort to standardize the various processes employed in his business, the very nature of which is such as to peculiarly resist efforts along this line. It not infrequently happens that attempts to reproduce former satisfactory results, fail, even though apparently all conditions remain exactly the same.

The kiln-burning is the process which usually comes in for the lion's share of the blame when such things happen, partly because it is the operation which uncovers all the errors and failures of the preceding operations, but largely because it is the process wherein direct control of, or contact with the material is, more nearly lost than in any other. Considerable has been written about terra cotta kilns, their design, construction, operation, etc.; but most of this has been directed toward the economical attainment of uniform heat-treatment, and the taking care of the major chemical changes such as dehydration, oxidation, etc., without very much regard to minor chemical reactions which may be taking place here and there throughout the kiln and which if not properly provided for or guarded against, many result in very unsatisfactory results.

It is not the intention of this paper to attempt to supply this deficiency, but rather to present a few notes on the result of an investigation on one or two of these minor changes, which are apt to be prolific sources of trouble.

\section{Sulphuring}

Nature of Trouble.-This phenomenon is one of the most frequent sources of trouble with which the manufacturer has to

${ }^{1}$ Received February 27, 1920. 
contend, in producing glazed material. It may result in bubbling, blistering, pin-holing or scumming, depending upon the amount involved and the time and conditions under which the action takes place. The nature of the defects produced has been discussed at length by Seger (Vol. 2, page 583 , Collected Writings), Burt (Vol. 2, page $x_{39}$, T. A. C. Soc.) and others and will not be repeated here.

Table I-Showing Per cent of $\mathrm{SO}_{3}$ Contained in Samples of Enamel

\begin{tabular}{|c|c|c|c|}
\hline $\begin{array}{l}\text { DRAWN FROM } \\
\text { Temp. } \\
\text { Degrees C }\end{array}$ & $\begin{array}{l}\text { VARIOUS KILNS AT } \\
\text { Kiln } 29 \\
\text { Per cent } \mathrm{SO}_{3}\end{array}$ & $\begin{array}{l}\text { DIFFERENT } \\
\text { Kiln } 28 \\
\text { Per cent } \mathrm{SO}_{3}\end{array}$ & $\begin{array}{c}\text { Temperatures } \\
\text { Kiln } 26 \\
\text { Per cent } \mathrm{SO}_{3}\end{array}$ \\
\hline 700 & I. 83 & 2.29 & 0.60 \\
\hline 725 & I. 92 & . & . \\
\hline 750 & 2.00 & . & $\ldots$ \\
\hline 775 & $3 \cdot 37$ & 3.28 & 3.95 \\
\hline 800 & 3.12 & $\ldots$ & .. \\
\hline 825 & 2.29 & 2.31 & 2.78 \\
\hline 850 & 2.33 & .. & $\ldots$ \\
\hline 875 & I. 94 & . & $\ldots$ \\
\hline
\end{tabular}

Investigation Made.-In an effort to obtain a little more information on the source, quantity, time and method of attack of this destructive agent in connection with the burning of terra cotta, an investigation was conducted over a period of several months on several different terra cotta kilns of the usual round, up-and-down draft, muffle type.

Presence of Sulphur.-Obviously the first step in the investigation was to prove the presence of sulphur in the enamel or glaze during the burning process. This was done by glazing a number of draw trials with a glaze free from sulphur and drawing them periodically up to about $875^{\circ} \mathrm{C}$, or until the glaze became too hard, scraping off the glaze and analyzing it for sulphur.

The results of this analyses (table I) showed clearly that the glaze did absorb an appreciable amount of sulphur trioxide in each of three different kilns, the maximum content (within the range covered) being at about $775^{\circ} \mathrm{C}$.

Source of Sulphur.-The presence of sulphur in the glaze having been clearly indicated, the next step was to investigate the source. Since the enamel had been found to be free of sulphur 
before going into the kiln (only a trace having been found on analysis), obviously the sources of same must be directly connected in some manner with the kiln-burning process. Of these there were the following possibilities:

(A) Clay.-The clay being used was known to contain a certain amount of sulphur both in the form of sulphates and as iron pyrites. In the case of the latter about one-half of its sulphur is distilled off as $\mathrm{SO}_{2}$ at about red heat, the final amount not leaving until about $900^{\circ} \mathrm{C}$. An average of several analyses of the clay being used at the time disclosed 0.048 per cent $\mathrm{SO}_{3}$ and 0.038 per cent $S$ (non-oxidized). While this would not be considered abnormally high, it is evident that the amount of sulphur driven off in a kiln of from 30 to 50 tons capacity, must be reckoned with, especially, when it is highly probable that the major portion of it leaves in a comparatively short time.

(B) Grog.-The importance of this material as a source of sulphur is largely dependent upon its porosity and the length of time and conditions under which it has been exposed to the weather. Freshly burned grog or vitreous grog may be considered practically free of sulphur. On the other hand, porous grog such as "overs," old fire brick, saggers, etc., when exposed to the weather may contain a considerable percentage of $\mathrm{SO}_{3}$, no doubt absorbed from the rain which has passed through smoky atmosphere. Samples of terra cotta "overs" which have weathered for four or five years have been found to contain as high as $0.10 \%$ $\mathrm{SO}_{3}$ on analysis.

(C) Coal.-The coal being used was that known as Indiana gas coal, the sulphur content of which varies greatly, but could not be considered abnormally high. An average of several analyses made at the time showed a total sulphur content of o.8o per cent $\mathrm{S}$. Theoretically, of course, in a muffle kiln (if the muffle were entirely impervious to gas), the presence of sulphur in the coal would have no effect on the atmosphere within the kiln chamber. Practically, however, as every kiln burner knows, it is impossible to exclude all the gases of combustion from the kiln chamber. This is shown conclusively by analyses of the kiln gases for sulphur (see table 2), where appreciable amounts of $\mathrm{SO}_{2}$ are found present at the very early stages of the burn $-200^{\circ} \mathrm{C}$ to $300^{\circ} \mathrm{C}-$ 
or long before the first of the sulphur is distilled from the clay. The only possible source of this sulphur is from the products of combustion. That we have then, to reckon with the sulphur in the coal, there can be no doubt.

Quantity of Sulphur.-There exists then these two main sources of sulphur, viz., clay and coal. The next logical step in the investigation was to determine, if possible, quantitative relationship in the sulphur content of the kiln gases, from one stage to another of the burn, as influenced by these two factors, with a view of adopting corrective measures where possible. The first efforts along this line consisted of an estimation of the $\mathrm{SO}_{2}$ in the kiln gases and combustion gases, periodically during the burn.

Bromine Absorption. - The method adopted was to draw a volume of five gallons of gas in each instance, allowing same to bubble through a series of flasks containing bromine water forming $\mathrm{H}_{2} \mathrm{SO}_{4}$, which was later precipitated as $\mathrm{BaSO}_{4}$ and calculated to milligrams of $\mathrm{SO}_{3}$ per 5 gallons of gas. These samples were drawn simultaneously from the kiln chamber, and from the flue gases, in order to determine what relationship, if any, might exist between the sulphur content of the gases from the two sources.

Typical results of these experiments, which were conducted on several different kilns are shown in table 2, for a coal-fired kiln and table 3 for a producer-gas fired kiln.

Table 2 - Showing Milligrams of $\mathrm{SO}_{3}$ Per 5 Gallons of Kiln Gas and COMBUSTION Gas at Various TEMPERATURES OF TXPICAL BURN-DIRECT COAL-FIRED KIIN

\begin{tabular}{|c|c|c|}
\hline $\begin{array}{l}\text { Te mp. } \\
\text { Degrees C }\end{array}$ & $\begin{array}{l}\mathrm{SO}_{3} \text { in muffe } \\
\mathrm{mmg} \text {. in } 5 \text { gal. }\end{array}$ & $\begin{array}{l}\mathrm{SO}_{3} \text { in flue } \\
\text { mmg. in } 5 \text { gal. }\end{array}$ \\
\hline 100 & . & I. 064 \\
\hline 200 & . & 10.000 \\
\hline 300 & I. 270 & . \\
\hline 400 & 3.260 & 8.580 \\
\hline 500 & 0.789 & 22.780 \\
\hline 600 & $0.86 \mathrm{I}$ & 5.733 \\
\hline 700 & 7.100 & 27.570 \\
\hline 800 & 3.780 & 2.400 \\
\hline 900 & 27.570 & $4 \cdot 460$ \\
\hline 1000 & 19.950 & $9.95^{\circ}$ \\
\hline
\end{tabular}


TABLE 3-Showing Militigrams of $\mathrm{SO}_{3}$ PER 5 Gat,Lons of KILN Gas and Combustion Gas at Various Temperatures of Typical, BURN OF KILN FIREd with Producer Gas

$\begin{array}{ccc}\begin{array}{c}\text { Temp. } \\ \text { Degrees } \mathrm{C}\end{array} & \begin{array}{c}\mathrm{SO}_{3} \text { in muffe } \\ \text { mmg. in } 5 \text { gal. }\end{array} & \begin{array}{r}\mathrm{SO}_{3} \text { in flue } \\ \text { mmg. in 5 gal. }\end{array} \\ 100 & \ldots . & \ldots \\ 200 & \text { None } & 5.3 \\ 300 & \text { Trace } & 0.82 \\ 400 & \text { Trace } & 4.98 \\ 500 & 3.2 & 12.53 \\ 600 & \text { None } & 2.13 \\ 700 & \text { None } & 2.13 \\ 800 & 2.4 & 11.87 \\ 900 & 15.86 & 3.78 \\ 1000 & \ldots . & \ldots\end{array}$

From these it will be seen that the attempt to establish a quantitative relationship between the $\mathrm{SO}_{3}$ in the flue gas and that in the kiln chamber for the temperatures below red heat was only partially successful. Generally speaking, the curves would follow the same general trend, but the relationship is not at all decisive. It would hardly be expected to be otherwise, however, as during this time all trial holes are open and the kiln chamber is well ventilated. Table 2 does show, however, as pointed out on page 479, that $\mathrm{SO}_{3}$ is present in the kiln chamber long before any sulphur leaves the clay

-Another interesting fact is brought out by comparing the results on a direct coal-fired kiln (table 2) with those on a producergas-fired kiln (table 3). Note that below $900^{\circ} \mathrm{C}$, when all the sulphur leaves the clay, the quantity of $\mathrm{SO}_{3}$ in the kiln seems to be considerably less for the producer gas-fired kiln than for the direct fired kiln. This difference was apparent on every producer gas-fired kiln examined, and is probably due to the more uniformfiring conditions and muffle wall temperatures which obtain with the former method. In direct firing there is a sudden cooling of the muffle walls each time a fresh charge of coal is fired, which tends to open up the joints and cracks more than usual. Coincident with this, the flue spaces are all crowded or chocked with excessive volumes of hydrocarbons and other volatile gases from the coal causing an abnormal pressure inward at this particular time, which results in excessive infiltration of the gases of com. 
bustion. That this condition exists, was demonstrated a number of times by analyses of samples taken at different times with respect to the time and manner of firing. In the gas-fired kilns, obviously it does not obtain.

Lime Absorption.-In order to get still further information on the relative intensity of the suphuring action during the progress of the burn a second series of experiments was conducted as follows: A small sample of hydrated lime was introduced into the kiln chamber at a distance of about ${ }_{5} 5$ inches from the muffle at the beginning of the burn and was withdrawn when the kiln reached $100^{\circ} \mathrm{C}$, and a fresh sample substituted and left till $200^{\circ}$ was reached, when another sample was introduced, and so on throughout the entire period of the burn. Each sample was then analyzed for $\mathrm{SO}_{3}$. It was believed that from the beginning up until the glaze was fused the rate of absorption of $\mathrm{SO}_{3}$ by the lime would be indicative of, or correlative with, the action of the same gas $\left(\mathrm{SO}_{3}\right)$ on the glazes.

Table 4-Showing Amount and Rate of Absorption of $\mathrm{SO}_{3}$ By Hydrated LIME DURING TYPICAL, BURN

$\begin{array}{cccc}\text { Hrs. } & \begin{array}{c}\text { Temp. } \\ \text { Degrees }\end{array} & \begin{array}{c}\text { Per cent } \\ \text { SOm in } \\ \text { sample }\end{array} & \begin{array}{c}\text { Rate of absorption, } \\ \text { per cent in } 10 \text { hrs. }\end{array} \\ 12 & 100 & 0.14 & 0.116 \\ 32 & 400 & .26 & .37 \\ 43 & 500 & .80 & .90 \\ 49 & 600 & .83 & 1.40 \\ 55 & 700 & .83 & 1.40 \\ 65 & 800 & 3.92 & 3.92 \\ 71 & 900 & 8.01 & 7.30 \\ 85^{1 / 2} & 1000 & 14.13 & 14.00 \\ 99 & 1050 & 14.3 & 11.0\end{array}$

Table 5-Showing Square Inches of Ventilating Openings, Top, Bottom and Total, for Same Burn as in Table 4

\begin{tabular}{crccc} 
Time interval & \multicolumn{1}{c}{ Temp. interval ${ }^{\circ} \mathrm{C}$} & Sq. in top & Sq. in bottom & Total \\
o to $47 \mathrm{hrs}$. & $0^{\circ}$ to $570^{\circ}$ & 276 & 190 & 476 \\
47 to $57 \mathrm{hrs}$. & $570^{\circ}$ to $720^{\circ}$ & 84 & 190 & 274 \\
57 to $68 \mathrm{hrs}$. & $720^{\circ}$ to $830^{\circ}$ & 20 & 190 & 210 \\
63 to $74 \mathrm{hrs}$. & $830^{\circ}$ to $890^{\circ}$ & 20 & 100 & 120 \\
74 to $84 \mathrm{hrs}$. & $890^{\circ}$ to $980^{\circ}$ & 20 & 10 & 30 \\
84 to 95 hrs. & $980^{\circ}$ to $1030^{\circ}$ & 26 & 10 & 36 \\
95 hrs. to finish & $1030^{\circ}$ to $1050^{\circ}$ & 26 & 0 & 26
\end{tabular}


From the quantity absorbed by each sample a rate of absorption was then computed in terms of per cent in ro hours, and a typical result given in table 4 .

Kiln Ventilation.-At this point it became evident that the method of ventilating the kiln chamber must necessarily have a very important effect on the extent of sulphuring action which takes place, and a study was made of the ventilating schedule of the same kiln. The only means available for expressing this ventilation, in quantitative terms, was in computing the area of the openings into the kiln chamber during the burn. These openings were divided into two classes-the bottom openings, through which fresh air was admitted, and the top or crown openings, through which the kiln gases were expelled. Table 5 shows the result of this computation. In order to facilitate the study of these conditions and their relation to each other chart I was prepared, on which, in addition to the usual time-temperative curve, are plotted curves representing the rate of absorption of $\mathrm{SO}_{3}$ by lime (per cent in ro hours), and the square inches of openings, bottom, top and total for ventilation.

Effect of Ventilation on $\mathrm{SO}_{3}$ in Kiln.-A study of these curves brings out several interesting points.

First: It is evident that the amount of $\mathrm{SO}_{3}$ absorbed prior to the time the clay begins giving off its sulphur is almost negligible in amount, in this instance. If, however, condensation were to take place during water smoking an appreciable amount of sulphuric acid would be deposited.

Second: It is important to note that as the ventilating curves drop, the absorption curves mount. It is not to be inferred that the former is the whole cause of the latter. After red heat is reached the rapid distillation of the sulphur from the clay would greatly influence the rise in the absorption curve, independent of the ventilation. It is clear, however, that in this particular instance the ventilation is sharply reduced at a very unfortunate time, and it seems reasonable to conclude that the rate of absorption would have been kept very much lower if such had not been the case.

Third: It would seem that the effective ventilating openings would be those in the crown, and that, therefore, they should always 
be kept equal to or greater than the bottom openings. In this instance after forty-eight hours the reverse is true.

Numerous experiments were then conducted with a view to reducing the amount of sulphur present by revising the ventilating schedule. These were only partially successful, however, as indicated by curve on chart $\mathrm{I}$, owing to encountering very serious

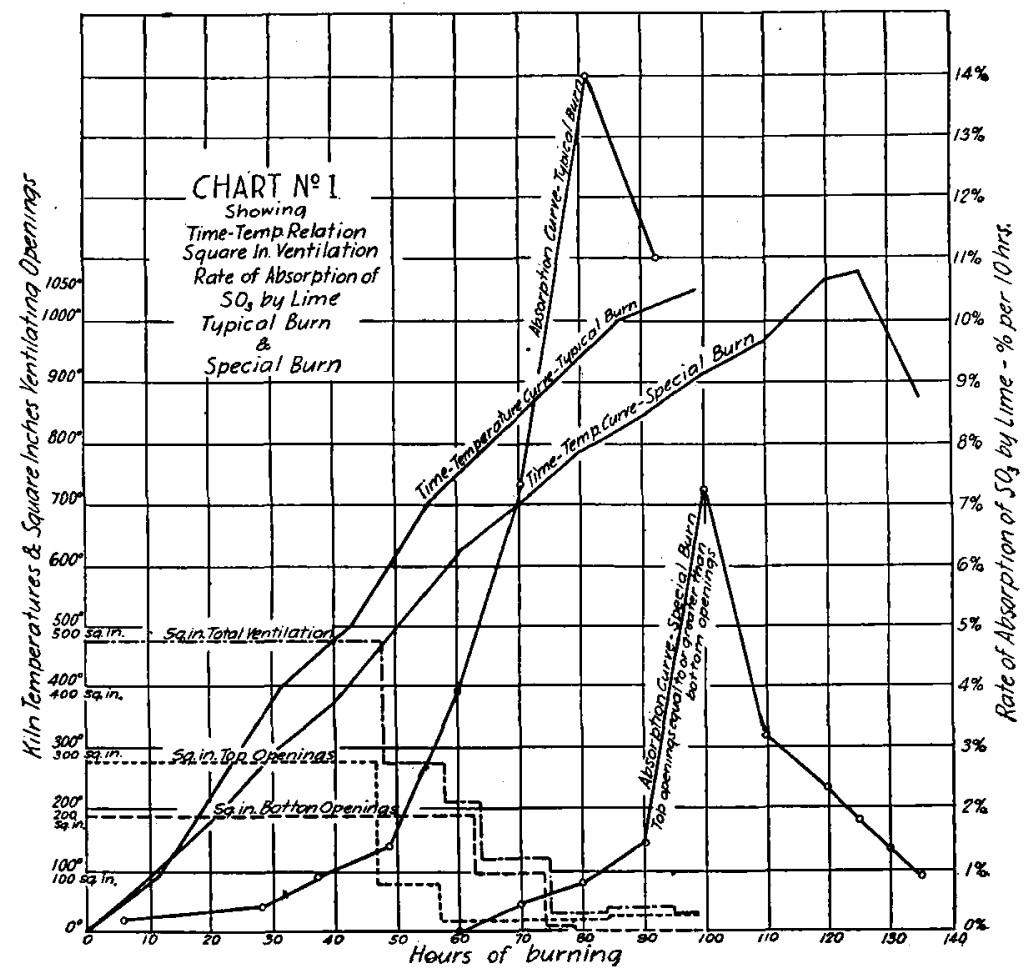

practical difficulties in maintaining satisfactory and uniform progress with the kiln, when the ventilation was carried too far. Weather and other variable conditions renders it impossible to predict in advance, in any except the most general terms, what the ventilating schedule of any particular kiln should be. The dangerous periods having been determined, it becomes the kiln burners problems on each kiln to provide the maximum ventila- 
tion at these times, with a minimum of detriment to the kiln's progress. One point, however, was very clearly established, viz., the necessity of adequate stack draft and flue capacity so that any difference in pressure that may exist between the kiln chamber and the flue will be exerted outward rather than inward.

Effect After Glaze Fusion.-During the course of this investigation the question arose as to whether the presence of $\mathrm{SO}_{3}$ was destructive after fusion of the glaze. To determine this, a small, freshly glazed unburned trial was enclosed with a previously burned trial of the same glaze, in a closed sagger into which were also introduced considerable pyrites grains. The piece being burned for the first time was entirely ruined, while the previously burned piece came out unchanged, from which it would seem that after fusion of the glaze has taken place, the $\mathrm{SO}_{3}$ has little or no effect, except of course, in the event that all of the gases have not been previously expelled from the body, or that conditions become reducing causing glaze to liberate sulphurous acid previously absorbed.

Conclusions.-A study of the data obtained by these experiments would seem to justify the following conclusions:

First: That there exists within the kiln chamber, in contact with the ware, an appreciable amount of $\mathrm{SO}_{3}$ gas practically from start to finish of the burn.

Second: That the source of this is from a leakage of combustion gases through the muffle wall, up until about red heat when the sulphur begins to distill from the pyrites in the clay.

Third: That owing to the excessive ventilation prevailing at the beginning of the burn, the $\mathrm{SO}_{3}$ is removed rapidly and does little damage.

Fourth: That after the glaze has fused it is not easily susceptible to chemical action of $\mathrm{SO}_{3}$ upon its surface.

Fifth: That the danger zone, therefore, lies between red heat and the time of fusion of the glaze, and is particularly troublesome because the sulphur being distilled as $\mathrm{SO}_{2}$ from the pyrites in the clay encounters a moist atmosphere due to the dehydration of the clay forming $\mathrm{H}_{2} \mathrm{SO}_{4}$ and at a time when the ventilaton is apt 
to be sharply .reduced by the closing of trial holes and crown openings.

Sixth: The sulphuric acid gas thus formed may be taken up by the glaze, either by physical absorption or chemical combination or both, and exert its destructive action in any of the following manners:

(A) Upon fusion of the glaze, $\mathrm{SO}_{2}$ may be displaced by $\mathrm{SiO}_{2}$ and escaping as a gas cause blisters. (Seger's Collected Writings, Vol. 2, page 647.) The extent of this action would be influenced by the silica content of the glaze and its tendency to dissolve silica from underslips or body. Seger found that a bi-silicate would hold 4 per cent of $\mathrm{H}_{2} \mathrm{SO}_{4}$ in solution while a tri-silicate would hold only 2 per cent. There is, therefore, a certain amount of $\mathrm{SO}_{2}$ and $\mathrm{O}$ to be expelled from the glaze saturated with $\mathrm{H}_{2} \mathrm{SO}_{4}$ whenever that glaze takes up any silica from the body or underslip.

It is probably not necessary, however, that the glaze be saturated with sulphates, in order that $\mathrm{SO}_{2}$ may be given off, especially if the kiln atmosphere becomes reducing. That such may be the case especially toward the end of the burn will be shown later, and no doubt herein lies the explanation of occasional blistering troubles. The glaze during the progress of the burn may have absorbed considerable $\mathrm{H}_{2} \mathrm{SO}_{4}$ from the kiln atmosphere but still be well below its saturation point. Fusion takes place and the glaze remains tranquil as long as oxidizing conditions prevail. However, if the kiln atmosphere then becomes reducing, especially at that high temperature, the $\mathrm{H}_{2} \mathrm{SO}_{4}$ and other sulphates are broken up and $\mathrm{SO}_{2}$ and $\mathrm{O}$ in escaping, or attempting to escape, through the molten glaze form blisters or produce a scummy appearance.

(B) The sulphuric acid may displace boric acid $\left(\mathrm{B}_{2} \mathrm{O}_{3}\right)$ from glazes containing same.

(C) $\mathrm{H}_{2} \mathrm{SO}_{4}$ may react with coloring oxides and other fluxes present, thus preventing maturity necessary for proper development of desired color and texture.

Seventh: The chances of trouble in this period may be very much lessened by: 
(A) Providing the maximum ventilation possible consistent with satisfactory progress of the kiln.

(B) Firing so as to avoid choking the flues with large volumes of gas.

(C) Maintaining adequate secondary air supply in the fire boxes.

(D) Maintaining adequate stack draft and oxidizing conditions throughout.

\section{Effect of Reducing Conditions}

The necessity for maintaining oxidizing conditions through the burn is so well recognized by the terra cotta manufacturer that he is apt to take it for granted that his kiln atmosphere is always safely oxidizing. Such, however, may not prove to be the case, and an examination in connection with trouble such as color variation on both glazed and standard material, fading or loss of color on glazes, occasional blistering or scumming, etc., may disclose that his kiln atmosphere is quite frequently apt to be deficient in oxygen.

During the course of the above investigation frequent Orsat analyses were made of both the combustion gases and the gases within the kiln itself. While results of these analyses would vary somewhat from one kiln to another or with weather conditions for the same kiln those shown on chart 2 indicate the general tendency, which is to approach dangerously close, and in some cases obtain, reducing conditions the last few hours of the burn.

Numerous experiments were made in the method of firing, of introducing the secondary air in the combustion gases, of ventilating the kiln chamber proper, etc. While some improvement was noted as a result of careful study of these conditions, uniformly satisfactory conditions were not obtained until the stack draft was decidedly increased by raising and enlarging the stacks.

The details of these experiments and the resulting data have been omitted for brevity, but they brought out very clearly the following interesting points:

First: That it is impractical to depend entirely upon direct admission of air through trial holes or other openings for main- 
tenance of oxidizing conditions, without retarding the progress of the kiln beyond practical limits.

Second: That after closing of all the trial holes and other openings into the kiln the oxygen is consumed very rapidly.

Third: That the oxygen is consumed much faster when the gases of combustion are allowed to become reducing or near re: ducing.

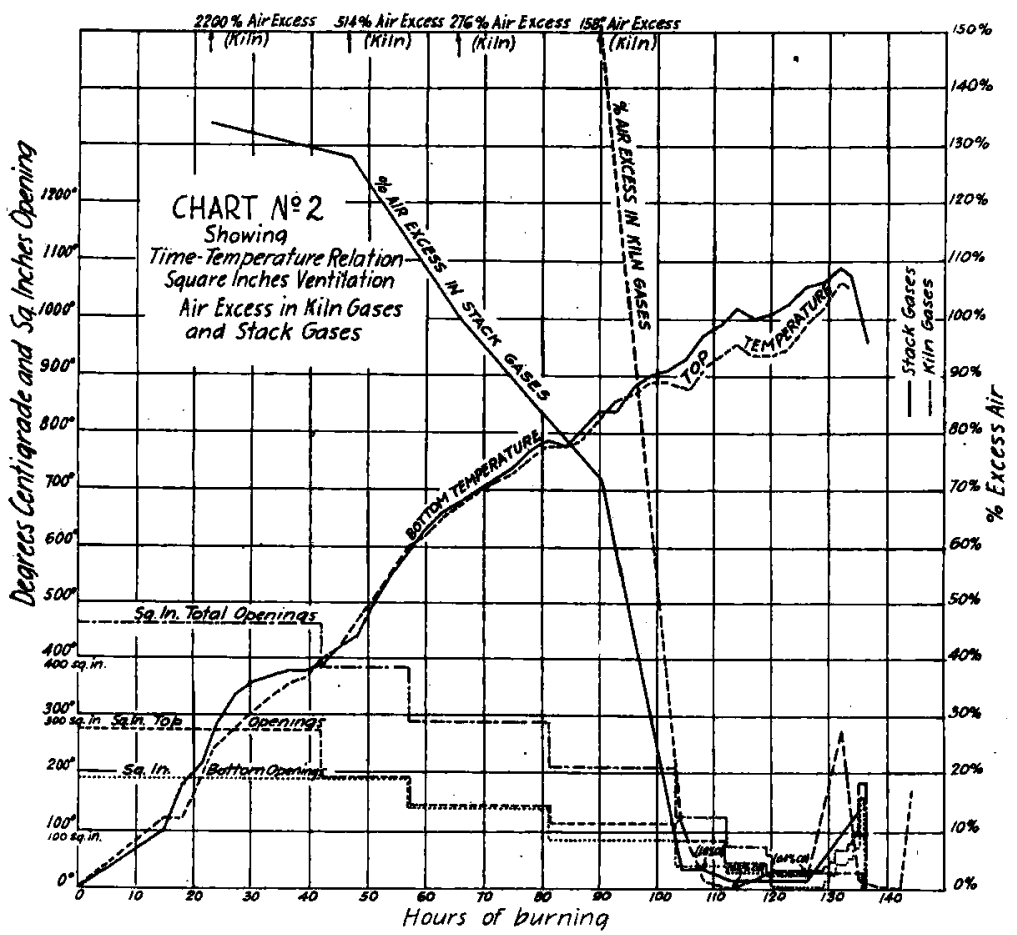

Fourth: That once the oxygen has been exhausted in the kiln chamber it is very difficult if not impossible to re-establish oxidizing conditions by admitting air into the combustion gases.

Fifth: That it is highly essential, therefore, that the combustion gases be kept safely oxidizing throughout, particularly after the trial holes are closed.

Sixth: That the setting up of reducing conditions, particularly after the glaze has fused may produce blistering, scumming, etc., 
on glazed work, by reason of reduction of sulphates previously absorbed and liberation of $\mathrm{SO}_{2}+\mathrm{O}$ through the molten glaze.

Seventh: That while the kind of coal, method of firing, construction of fire box and secondary air supply, all have an important bearing on the maintenance of this condition, the first and most important factor is an adequate draft, without which, in the ordinary up-and-down draft muffle kiln, occasional reducing conditions are inevitable.

Northwestern Terra Cotta Co.

$$
\text { Chicago, Ili.. }
$$

Norrce.-Further discussion of this subject is solicited. All communications should be sent to the Editor. 